\title{
Bioactive nanocrystalline wollastonite synthesized by sol-gel combustion method by using eggshell waste as calcium source
}

\author{
U ANJANEYULU and S SASIKUMAR* \\ Centre for Excellence in Nanomaterials, School of Advanced Sciences, VIT University, Vellore 632 014, India
}

MS received 4 July 2012;

\begin{abstract}
The sol-gel combustion method was employed to synthesize the nanocrystalline wollastonite by taking the raw eggshell powder as a calcium source and TEOS as a source of silicate. Glycine was used as a reductant or fuel and nitrate ions present in metal nitrate acts as an oxidizer. The phase purity of the wollastonite was analysed by powder XRD and the product is found to contain single-phasic wollastonite. FT-IR spectrum shows the characteristic peaks of the functional groups present in the wollastonite. SEM images show that particles are agglomerated and the particle size is found to be in the nanoregime. The calcination temperature was optimized based on the thermal analysis of the precursor. The bioactivity of wollastonite was investigated by immersing the scaffold in a simulated body fluid for 15 days at $37^{\circ} \mathrm{C}$ and intermediate analysis of the surface by XRD shows the deposition of hydroxyapatite layer after 5 days.
\end{abstract}

Keywords. Bioceramic; raw eggshell powder; sol-gel combustion; bioactivity; hydroxyapatite.

\section{Introduction}

Ceramics like wollastonite, hydroxyapatite (HA), $\beta$-tricalcium phosphate are the various bioceramics have shown to bond with living bone directly hence, they received important attention in the field of biomedical engineering as a significant bone substitute (Sainz et al 2010). The characteristic of a bioactive material is its ability to form hydroxyapatite layer on its surface in presence of physiological environment, which provides the bonding interface with the tissues and bone (Wei et al 2009). Calcium silicate ceramics were used as an alternate for hydroxyapatite in the biomedical applications like artificial dental roots and as a bone regenerative material (Wang et al 2008). Calcium silicates are also used in industrial, technological applications due to its properties like high temperature strength, creep resistance, chemical inertness, thermal stability, low thermal expansion and low thermal conductivity (Sreekanth Chakradhar et al 2006).

Wollastonite belongs to the group of bioactive and biocompatible calcium silicates. In recent years wollastonite has received much attention due to its high bioactivity and biocompatibility which influenced the researchers to study its application in the field of drug delivery system. The bioactivity of wollastonite is higher than any of the other biocompatible glass and glass ceramics. The bioactivity of calcium silicate was analysed by the rate of hydroxyapatite formation on its surface in presence of simulated body fluid (SBF) (Huang and Chang 2009). The bioactivity of wollastonite is

\footnotetext{
*Author for correspondence (ssasikumar@vit.ac.in)
}

due to silicon ion present in it, as it plays an essential role in the formation of new bone by metabolic process. Wollastonite shows an excellent bone-bonding ability than the hydroxyapatite and tricalcium phosphate (Kobayashi et al 1998).

The preparation of wollastonite was reported for hydrothermal method (Lin et al 2006), sol-gel method (Meiszterics and Sinko 2008), solution combustion method (Sreekanth Chakradhar et al 2006), co-precipitation (Binnaz Yoruc and Hazar 2007), citrate-nitrate gel combustion method (Huang and Chang 2009) and microwave synthesis (Vichaphund et al 2011). The preparation procedure plays a vital role in the bioactivity of the calcium silicates as the solgel synthesized wollastonite is found to have higher bioactivity than the wollastonite prepared by solid-state method. However, the agglomerates produced were homogeneous in sol-gel synthesis than the products synthesized by any of the above mentioned methods (Ortega-Lara et al 2010). The phase transformation temperature of the solution combustion synthesized wollastonite powder was found to be lower than the powders obtained by solid-state method (Sreekanth Chakradhar et al 2006).

The sol-gel combustion process is a combination of solgel and combustion syntheses. In sol-gel combustion process the vigorous redox reaction between the fuel and oxidant is highly exothermic and releases large amount of heat energy at which the phase formation is completed for most of the compounds hence the calcination temperature is found to be lower for this method when compared to the sol-gel method, combustion method and solid-state method. Wollastonite synthesized by microwave method by using biowaste and eggshell as a source of calcium is found to possess a good 
bioactivity (Vichaphund et al 2011). Wollastonite synthesized by the pyrolysis of chicken eggshells followed by solgel process and the product was reported to possess dielectric property and it is used in the field of biomedical engineering (Tangboriboon et al 2011).

In the present work, we are reporting the synthesis of wollastonite by sol-gel combustion method, by using glycine as a fuel and raw eggshell powder as a calcium source. The product formed was analysed for its in vitro bioactivity in the simulated body fluid medium.

\section{Experimental}

\subsection{Materials}

Chicken eggshell, glycine (Qualigens fine 98\%), tetraethyl orthosilicate (Acros organics 98\%), concentrated nitric acid, hydrochloric acid, sodium chloride (s.d. fine 99.9\%), sodium bicarbonate (nice chemical 99\%), potassium chloride (s.d. fine $99.5 \%$ ), dipotassium hydrogen phosphate (s.d. fine 99\%), calcium chloride (Qualigen fine 98\%), magnesium chloride (Ranbaxy 97\%), sodium sulphate (s.d. fine 99.5\%) and tris hydroxymethylate aminomethane (s.d. fine 99\%) were used.

\subsection{Experimental procedures}

The chicken eggs were collected from Vellore market and boiled in beaker containing water for $20 \mathrm{~min}$ on Bunsen burner. The eggshells were removed and dried in hot air oven at $120^{\circ} \mathrm{C}$ for $2 \mathrm{~h}$. The raw eggshell is grinded in mortar and pestle for $30 \mathrm{~min}$ to get fine powders.

The fine powder of eggshell was reported to contain $94.37 \% \mathrm{CaCO}_{3}$, hence in order to prepare $1 \mathrm{M} \mathrm{Ca}^{2+}$ ion solution $10 \mathrm{~g}$ of raw eggshell was taken and dissolved in $5 \mathrm{ml}$ con. $\mathrm{HNO}_{3}$. The unreacted constituents of eggshell were filtered by Watmann 41 filter paper and the resultant solution was made up to $100 \mathrm{ml}$. This solution with approximately $1 \mathrm{M}$ concentration of $\mathrm{Ca}^{2+}$ ions is used as a stock solution for further experiments.

\subsection{Estimation of $\mathrm{Ca}^{2+}$ ions in eggshell solution}

The concentration of calcium ions present in the raw eggshell solution was estimated by complexometric titration and flame photometry. In flame photometry $\mathrm{CaCl}_{2}$ $(0 \cdot 277 \mathrm{~g} \backslash 100 \mathrm{ml})$ was taken as a standard solution to plot the standard graph and the stock solution prepared from eggshell was sufficiently diluted and analysed for the concentration of $\mathrm{Ca}^{2+}$ ions.

In the complexometric titration, $\mathrm{CaCO}_{3}(0 \cdot 1 \mathrm{~g} \backslash 100 \mathrm{ml})$ dissolved in $\mathrm{HCl}$ and made up to $100 \mathrm{ml}$ was taken as a standard solution and EDTA was taken as a complexing agent. From the standard solution the concentration of calcium present in eggshell solution was estimated after sufficient dilution and it was found to be $0.01 \mathrm{M}$.

\subsection{Synthesis of wollastonite}

The stoichiometric ratios of eggshell solution and glycine solution were taken and mixed thoroughly. Tetraethyl orthosilicate (TEOS $1 \mathrm{M}$ ) was added to the above mixture with constant stirring for $10 \mathrm{~min}$ at room temperature. The rate of hydrolysis of TEOS is slow in neutral solutions and requires an acid or base catalyst hence the $\mathrm{pH}$ of the solution was adjusted to 1 by adding concentrated nitric acid. The resultant solution was stirred constantly and the temperature was rised to $40{ }^{\circ} \mathrm{C}$ and maintained for $90 \mathrm{~min}$ in a covered glass beaker. The thick gel formed was dried at $100^{\circ} \mathrm{C}$ for $7 \mathrm{~h}$ and the decomposition of the gel was carried out at $400^{\circ} \mathrm{C}$ for $2 \mathrm{~h}$ in muffle furnace. The precursor formed was calcined at $900^{\circ} \mathrm{C}$ for $12 \mathrm{~h}$ results in a white product which was analysed by powder XRD in order to check the phase purity.

\subsection{Preparation of scaffold}

$200 \mathrm{mg}$ of the calcined wollastonite powder was made into scaffold by applying 7 tons of pressure in hydraulic pellet press with the scaffold diameter of 12 and $3 \mathrm{~mm}$ thickness for the bioactivity studies.

\subsection{In vitro bioactivity assessment of scaffold in simulated body fluid}

Simulated body fluid (SBF) was prepared by other procedures by dissolving $\mathrm{NaCl}, \mathrm{NaHCO}_{3}, \mathrm{KCl}, \mathrm{K}_{2} \mathrm{HPO}_{4} \cdot 3 \mathrm{H}_{2} \mathrm{O}$, $\mathrm{MgCl}_{2} \cdot 6 \mathrm{H}_{2} \mathrm{O}, \mathrm{CaCl}_{2}, \mathrm{Na}_{2} \mathrm{SO}_{4},\left(\mathrm{CH}_{2} \mathrm{OH}\right)\left(\mathrm{NH}_{2}\right)$ in deionized water and $\mathrm{HCl}$ solution was added to adjust the $\mathrm{pH}$ 7.25. The prepared simulated body fluid has the ionic concentration similar to human blood plasma (Siriphannona et al 2002; Wei et al 2009). The in vitro bioactivity of wollastonite scaffold was investigated by placing the scaffold in $15 \mathrm{ml}$ simulated body fluid (SBF) kept at $37^{\circ} \mathrm{C}$ in an incubator with the replacement of the simulated body fluid at the end of every $24 \mathrm{~h}$. The scaffold was removed at various time periods and analysed for the growth of hydroxyapatite (HAp) layer on the surface of the scaffold (Raquez et al 2011). The scaffold was dried at $80^{\circ} \mathrm{C}$ for $15 \mathrm{~min}$ in a hot air oven, the formation of the hydroxyapatite layer on the surface of wollastonite was analysed by powder XRD on $5^{\text {th }}, 10^{\text {th }}$ and $15^{\text {th }}$ day of incubation.

\subsection{Characterization}

Phase identification was done by using Bruker D8 Advance $\mathrm{X}$-ray diffractometer, using $\mathrm{CuK} \alpha(1.5406 \AA)$ and Ni filtered radiation. The functional groups were identified using FTIR spectrometer (Shimadzu). SEM images were recorded by using Hitachi S-3400N Model, at an accelerating voltage of $15 \mathrm{kV}$. The thermodynamic property of precursor was studied by the thermo-gravimetric analyser (TGA) and differential thermal analyser (DTA). In vitro bioactivity studies were carried out in orbital shaking incubator RIS-24B. 


\section{Results and discussion}

When eggshell is dissolved in concentrated nitric acid, $\mathrm{CaCO}_{3}$ ions present in the eggshell will get converted to $\mathrm{Ca}\left(\mathrm{NO}_{3}\right)_{2}$. $\mathrm{pH}$ is adjusted to 1 by adding concentrated nitric acid, the tetraethyl orthosilicate in acidic medium will undergo hydrolysis and results in the formation of alcohol and $\mathrm{Si}(\mathrm{OH})_{4}$. The resultant $\mathrm{Si}(\mathrm{OH})_{4}$ reacts with $\mathrm{Ca}^{2+}$ ions present in the eggshell solution to form amorphous $\mathrm{CaSiO}_{3}$. Glycine plays a major role as a fuel for the combustion. When the mixture was stirred, hydrolysis of TEOS results in the formation of ethyl alcohol which undergoes condensation reaction with the glycine and forms a polymeric network. The nitrate ions from eggshell solution and nitric acid added for hydrolysis will act as an oxidizer during the decomposition of gel and results in an exothermic reaction. The high temperature evolved during combustion aids in the phase formation of wollastonite.

\subsection{Fourier transform infrared spectroscopy}

FTIR spectrum was recorded in the range of $400-4000 \mathrm{~cm}^{-1}$, with the resolution of $4 \mathrm{~cm}^{-1}$. FT-IR spectrum (figure 1a) of raw eggshell show peaks at 712, 874, 1459 and $2519 \mathrm{~cm}^{-1}$ which are the characteristic peaks of $\mathrm{CaCO}_{3}$, the absorption that occurred around 1798, 2880 and $2982 \mathrm{~cm}^{-1}$ correspond to $\mathrm{C}=\mathrm{O}$ from carbonate ion $\left(\mathrm{CO}_{3}^{-2}\right)$. The very strong band at $1459 \mathrm{~cm}^{-1}$ is related to the carbonate $\mathrm{C}-\mathrm{O}$ bonds, band at around $588 \mathrm{~cm}^{-1}$ corresponds to $\mathrm{Ca}-\mathrm{O}$ bonds. And the broad band at $3413 \mathrm{~cm}^{-1}$ corresponds to the moisture

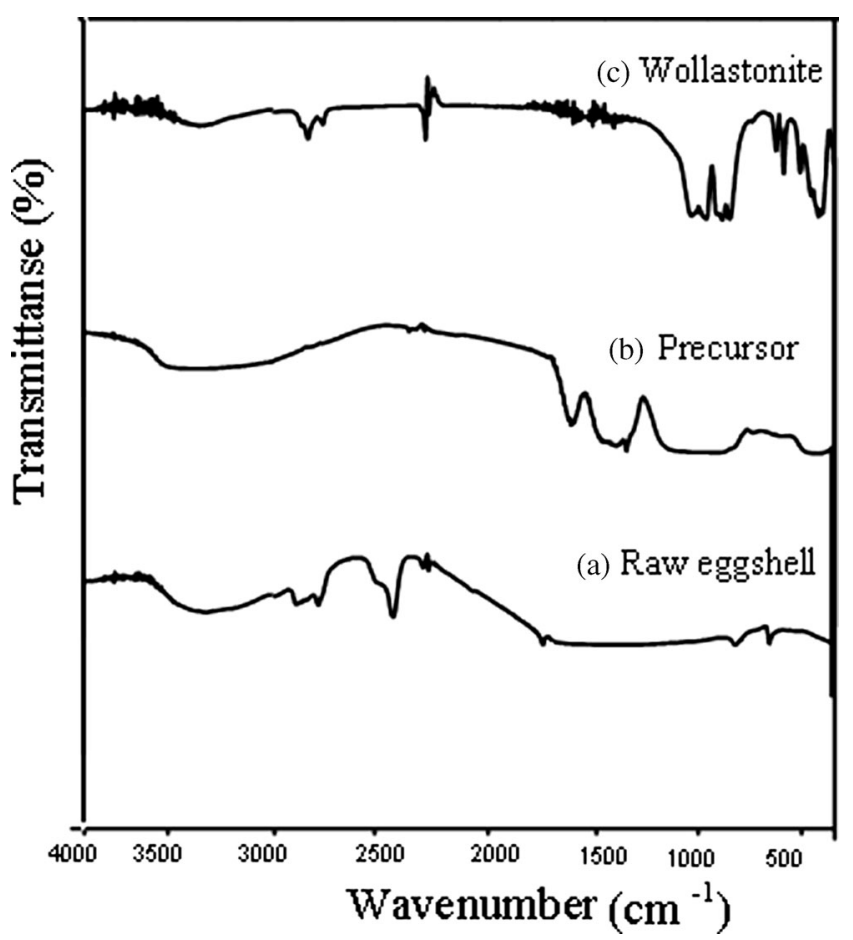

Figure 1. FTIR spectra of the (a) raw eggshell powder, (b) precursor and (c) wollastonite. absorption on the surface of the pellet (Wang et al 2006; Miguel Galván-Ruiz et al 2009). Figure 1(b) shows peaks at $470-1023 \mathrm{~cm}^{-1}$ due to $\mathrm{Si}-\mathrm{O}, \mathrm{O}-\mathrm{Si}-\mathrm{O}, \mathrm{Si}-\mathrm{O}-\mathrm{Ca}, \mathrm{Si}-\mathrm{O}-\mathrm{Si}$ groups and $1471-1641 \mathrm{~cm}^{-1}$ due to stretching vibration of carbonate ions.

Figure 1(c) shows bending modes of $\mathrm{Si}-\mathrm{O}-\mathrm{Si}$ and $\mathrm{O}-\mathrm{Si}-$ $\mathrm{O}$ bonds at $476 \mathrm{~cm}^{-1}$, stretching modes of $\mathrm{O}-\mathrm{Si}-\mathrm{O}$ bonds at $798 \mathrm{~cm}^{-1}$, Si-O-Ca bonds containing non-bridging oxygen at $910-944 \mathrm{~cm}^{-1}$. The symmetric stretching vibrations of $\mathrm{Si}-\mathrm{O}-\mathrm{Si}$ bonds were observed at $1022-1083 \mathrm{~cm}^{-1}$ and bending vibration of $\mathrm{H}_{2} \mathrm{O}$ at $1630 \mathrm{~cm}^{-1}$. The band at $3437 \mathrm{~cm}^{-1}$ is due to the absorption of moisture on the surface of the wollastonite. The carbonate ions present in traces in the precursor is completely removed from the product by calcining at $900{ }^{\circ} \mathrm{C}$ for $12 \mathrm{~h}$.

\subsection{X-ray diffraction}

Figure 2 shows XRD pattern of the precursor calcined at $900{ }^{\circ} \mathrm{C}$ for $12 \mathrm{~h}$ and the peaks in the pattern is indexed to wollastonite (JCPDS file no: 043-1460). XRD pattern shows a single phasic wollastonite and no other secondary phases or unreacted starting materials were observed. The space group of wollastonite is $P 21 / a(14)$ and crystal symmetry is monoclinic respectively. The lattice parameter calculated from the powder XRD were found to be $a=15.463, b=7.342$ and $c=7.193 \AA$.

The average crystallite size $(D)$ of wollastonite was estimated from the full width at half-maximum (FWHM) of the powder XRD pattern using Scherrer's formula (Klug and Alexander 1962).

$$
D=k \lambda / B \cos \theta,
$$

where $\lambda$ is the wavelength of X-ray, $\theta$ the Bragg angle and $k$ is the constant depends on the grain shape $(0.89 \AA$ for circular grains). The calculated result shows the average crystallite size of the calcined $\mathrm{CaSiO}_{3}$ samples in the range of $42 \cdot 0 \mathrm{~nm}$.

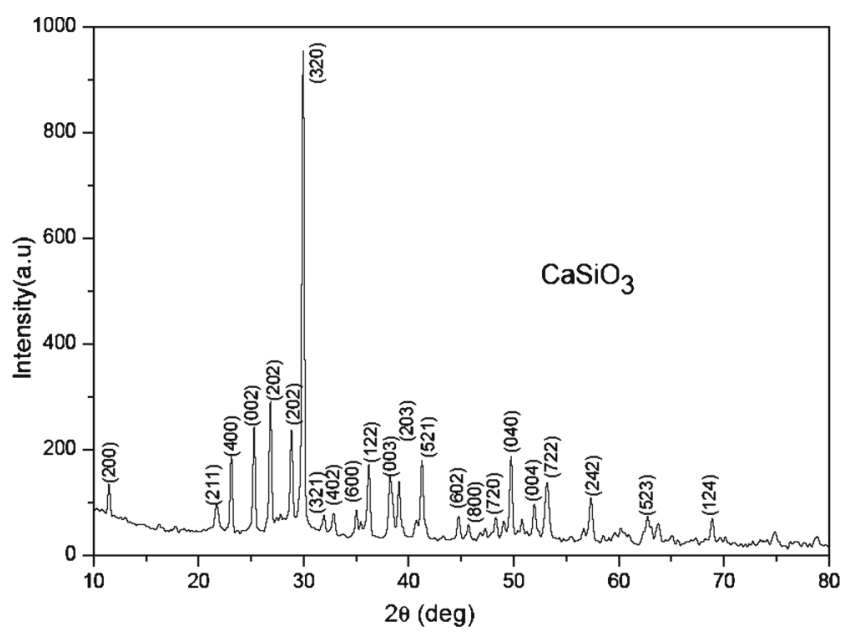

Figure 2. XRD pattern of the wollastonite synthesized by using eggshell as a calcium source. 


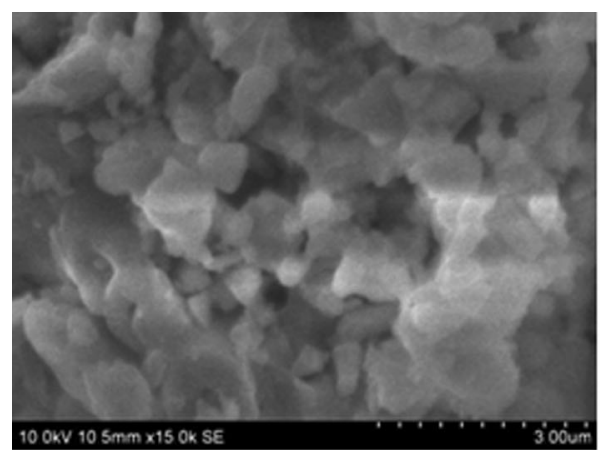

(a)

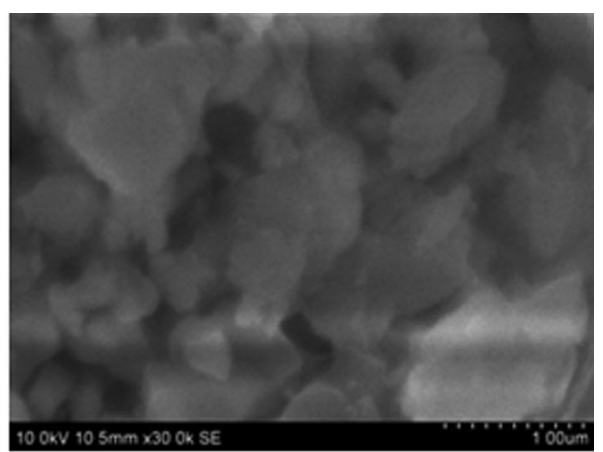

(b)

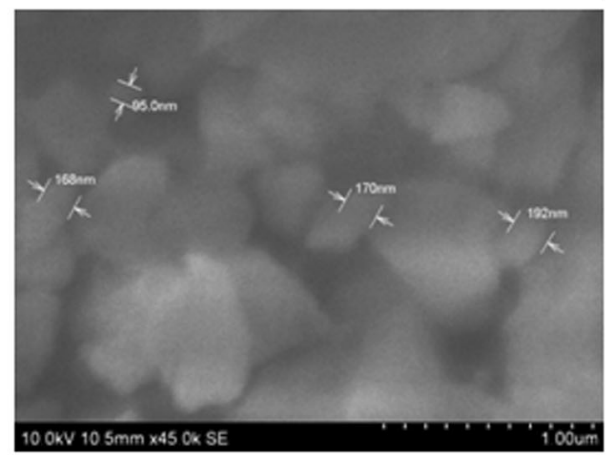

(c)

Figure 3. SEM images of the calcined wollastonite powder at $900^{\circ} \mathrm{C}$ for $12 \mathrm{~h}$.

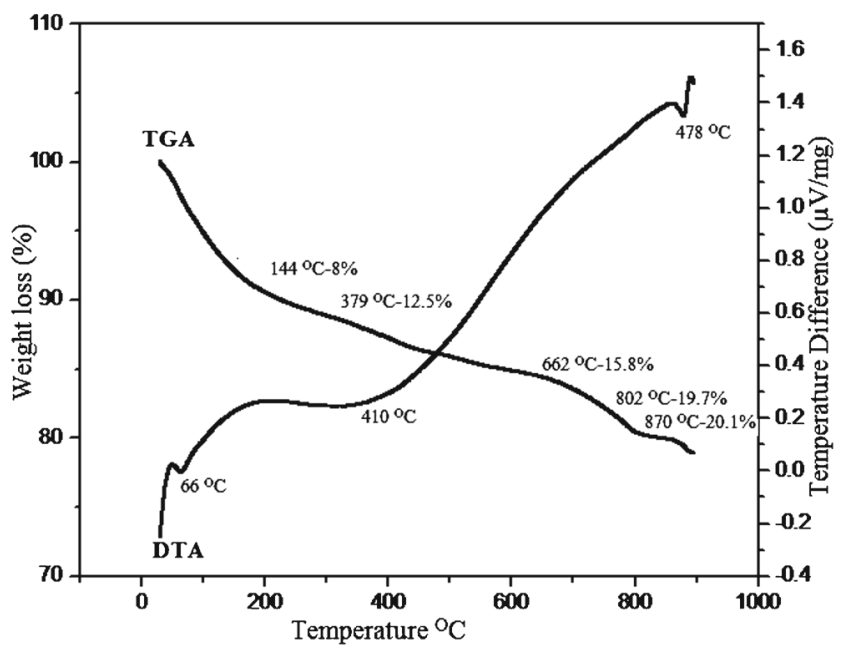

Figure 4. TGA and DTA curves for the precursor.

\subsection{Scanning electron microscopy}

SEM micrographs (figure 3) of the calcined wollastonite powders show that the synthesized wollastonite powders possess irregular morphology. Figure 3(c) shows that particle size of wollastonite powder is in the nano-regime and the particles are highly heterogenous. The particle size is in the range of 95-192 nm, which is in agreement with the particle size values calculated from XRD pattern by using Scherrer's equation. Figure 3(a and b) shows that powder is highly

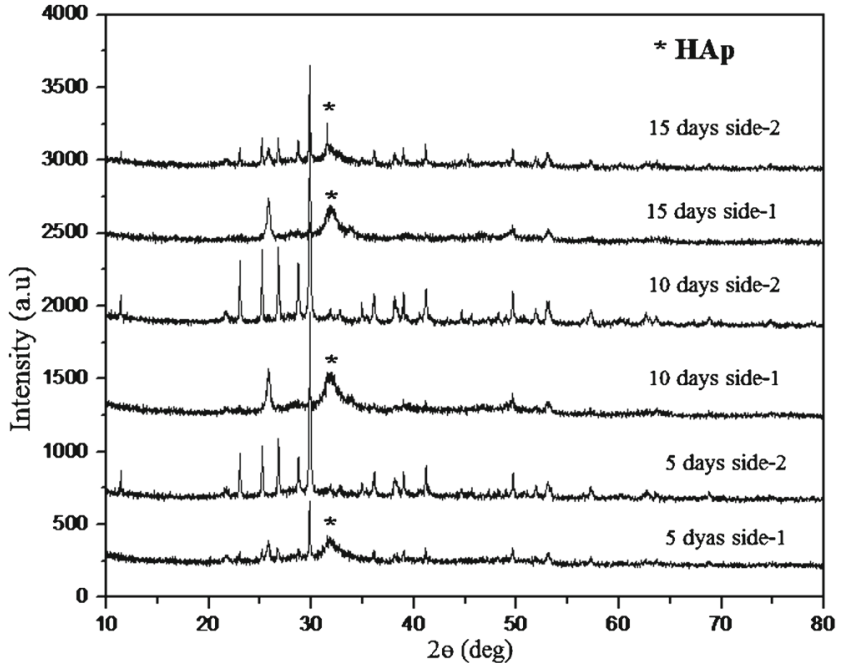

Figure 5. XRD pattern of the HAp deposit on the wollastonite for 5,10 and 15 days.

agglomerated with high porosity which will result in high surface area.

\subsection{Thermal analysis}

Thermal decomposition (figure 4) of the precursor was examined by the thermo gravimetric analyser (TGA) and 


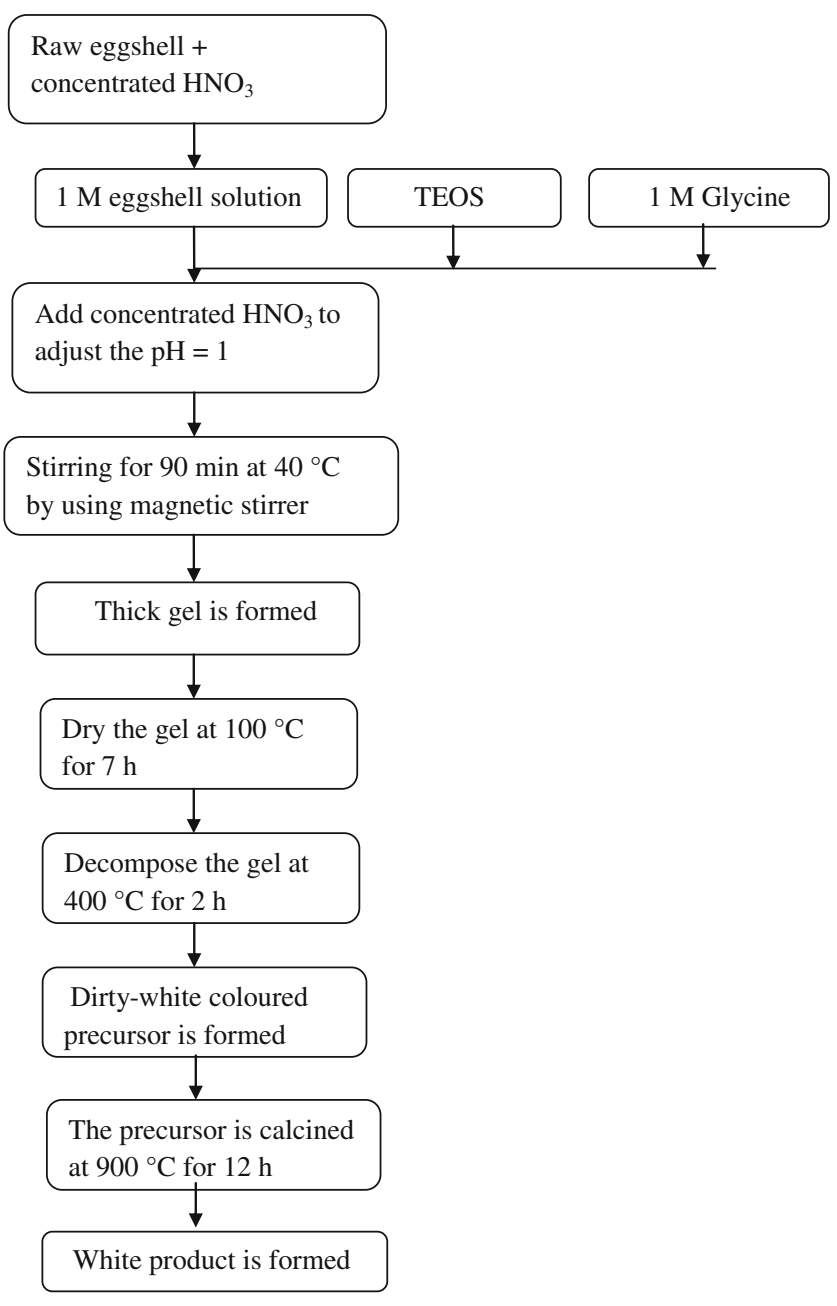

Flow chart for the synthesis of nanocrystalline wollastonite by solgel combustion method.

differential thermal analyser (DTA) with the heating rate of $10{ }^{\circ} \mathrm{C} \min ^{-1}$ in the nitrogen atmosphere. TGA curve shows $8 \%$ weight loss at $144{ }^{\circ} \mathrm{C}$ is due to the evaporation of moisture from the precursor, $12.5 \%$ weight loss at $379{ }^{\circ} \mathrm{C}$ may be due to the loss of nitrates and some glycine moieties, $17.5 \%$ weight loss at $600-802{ }^{\circ} \mathrm{C}$ may be due to the removal of carbon particles and the decomposition of $\mathrm{CaCO}_{3}$ present in the mixture. DTA curve shows sharp endothermic peak at $66{ }^{\circ} \mathrm{C}$ due to the loss of water molecules, the broad endothermic peak observed at $410{ }^{\circ} \mathrm{C}$ is due to the loss of nitrates and the sharp endothermic peak at $878{ }^{\circ} \mathrm{C}$ is due to the phase transformation (Wang et al 2008). From TGADTA, the gradual phase formation was observed at $870{ }^{\circ} \mathrm{C}$, hence the calcination temperature is optimized at $900^{\circ} \mathrm{C}$.

\subsection{Analysis of HAp formation on wollastonite pellets}

The in vitro bioactivity of the wollastonite scaffold was studied by placing the scaffold in the simulated body fluid. The scaffold was immersed in SBF solution for 15 days in an incubator at $37^{\circ} \mathrm{C}$ with the change of SBF after every $24 \mathrm{~h}$ and the phase composition of the scaffold surface was examined by XRD in order to check the deposition of hydroxyapatite. When $\mathrm{CaSiO}_{3}$ scaffold is immersed in $\mathrm{SBF}$, calcium and silicon ions get released from its structure and reacts with the other constituents present in the simulated body fluid. Calcium ions released from the surface of wollastonite coating is found to increase the ionic activity of the apatite formation in SBF leading to the formation of hydroxyapatite on the coated surface (Xuanyong Liu et al 2004; Paluszkiewicz et al 2008).

XRD pattern (figure 5) shows formation of hydroxyapatite on the surface of wollastonite at the end of $5^{\text {th }}, 10^{\text {th }}$ and $15^{\text {th }}$ day of incubation. Fifth and tenth days XRD pattern of side 1 shows more deposition when compared with side 2 which may be due to the more circulation of SBF on side 1 as it is exposed to SBF. Side 2 is kept over the glass beaker hence the circulation of SBF is very poor and as a result the deposition of hydroxyapatite is found to be very less. The scaffold was kept for 5 more days by reversing the sides, the analysis on $15^{\text {th }}$ day shows the deposition of apatite layer on both the sides which indicates that the circulation of SBF on the surface of the scaffold favours the deposition of hydroxyapatite layer.

\section{Conclusions}

Single phasic wollastonite $\left(\mathrm{CaSiO}_{3}\right)$ was successfully synthesized by sol-gel combustion method by using glycine as a fuel and raw eggshell as a source of calcium. The phase purity of the product was found to be very high and the particle size was found to be in the nano regime. The scaffold prepared from the wollastonite shows a very good bioactivity on the surface where the circulation of SBF is high and it shows poor or no activity on the surface where circulation of $\mathrm{SBF}$ is low. From the reports, we conclude that the method is effective in converting a biowaste in to a useful bioceramics.

\section{Acknowledgements}

The authors thank the VIT management for the financial support. The authors express their sincere gratitude to Prof $\mathrm{R}$ Vijayaraghavan (Assistant Director, Centre for Excellence in Nanomaterials, VIT University) for his continuous support and motivation.

\section{References}

Binnaz Yoruc A and Hazar 2007 J. Ceram. Int. 33687

Chengyu Wang, Ping Xiao, Jingzhe Zhao, Xu Zhao, Yanhua Liu and Zichen Wang 2006 Powder Technol. 17031

Huanping Wang, Qilong Zhang, Hui Yang and Huiping Sun 2008 Ceram. Int. 341405

Jie Wei, Fangping Chen, Jung-Woog Shin, Hua Hong, Chenglong Dai, Jiancan Su and Changsheng Liu 2009 Biomaterials 301080 Kaili Lin, Jiang Chang and Jianxi Lu 2006 J. Mater. Lett. 603007 
Klug H and Alexander L 1962 X-ray diffraction procedures (New York: Wiley) p. 491

Kobayashi M, Nakamura T, Okada Y, Fukumoto A, Furukawa T, Kato H, Kokubo T and Kikutani T 1998 J. Biomed. Mater. Res. 42223

Meiszterics A and Sinko K 2008 Colloids Surf. A319 143

Miguel Galván-Ruiz, Juan Hernández, Leticia Baños, Joaquín Noriega-Montes and Mario E Rodríguez-García 2009 J. Mater. Civ. Eng. 21694

Nuchnapa Tangboriboon, Tunchanoke Khongnakhon, Supawinee Kittikul Ruksapong Kunanuruksapong and Anuvat Sirivat 2011 J. Sol-Gel Sci. Technol. $\mathbf{5 8} 33$

Ortega-Lara W, Cortes-Hernandez D A, Best S, Brooks R and Hernandez-Ramirez A 2010 Ceram. Int. 36513

Paluszkiewicz C, Blazewicz M, Podporska J and Gumuła T 2008 Vib. Spectrosc. 48263
Punnama Siriphannona, Yoshikazu Kameshima, Atsuo Yasumori, Kiyoshi Okada and Shigeo Hayashi 2002 J. Eur. Ceram. Soc. 22 511

Raquez J M, Barone D T J, Luklinska Z, Persenaire O, Belayew A, Eyckmans J, Schrooten J and Dubois Ph 2011 J. Biomacro. 12 692

Sainz M A, Pena P, Serena S and Caballero A 2010 Acta Biomater. 62797

Sreekanth Chakradhar R P, Nagabhushana B M, Chandrappa G T, Ramesh K P and Rao J L 2006 Mater. Chem. Phys. 95169

Vichaphund S, Kitiwan M, Atong D and Thavorniti P 2011 J. Eur. Ceram. Soc. 312435

Xiang-Hui Huang and Jiang Chang 2009 Mater. Chem. Phys. 1151

Xuanyong Liu, Chuanxian Ding and Chu Paul K 2004 Biomaterials 251755 